\title{
Hesio Cordeiro e o Instituto de Medicina Social
}

| ${ }^{1}$ Reinaldo Guimarães |

${ }^{1}$ Núcleo de Bioética e Ética Aplicada, Universidade Federal do Rio de Janeiro. Rio de Janeiro-RJ, Brasil (reinaldo.guimaraes47@gmail.com).
ORCID: 0000-0002-0138-9594
Recebido em: 02/06/2021
Aprovado em: 03/08/2021
Revisado em: 23/08/2021
DOI: http://dx.doi.org/10.1590/\$0103-73312021310307

Para o nosso amigo comum, o querido João Regazzi Gerk, que testemunhou e atuou em tudo o que aqui vai.

Este texto visa resgatar a memória e homenagear a grande figura que acaba de nos deixar. Aliás, o desaparecimento físico de Hesio sucedeu a uma longa e penosa doença que lentamente promoveu uma primeira morte, lenta e dolorosa, de sua vida de relação. Na última vez que estive com ele, no início de 2020, já não conseguia estabelecer um contato pleno com o mundo que o cercava. Com sua morte, perdemos todos, a família, os amigos, a comunidade acadêmica da saúde, o SUS e o Brasil. Aqui, trataremos apenas os primeiros 15 anos de atividade intelectual e política de Hesio, exercida em boa parte no Instituto de Medicina Social da Universidade do Estado do Rio de Janeiro.

A pré-história do Instituto de Medicina Social (IMS) começa em 1965, quando o professor Américo Piquet Carneiro (1909-1992), titular de Clínica Médica da Faculdade de Ciências Médicas (FCM), um democrata liberal católico e progressista, 
criou um ambulatório de medicina comunitária no Hospital Pedro Ernesto, vinculado à faculdade. Em seguida, em 1966, também inspirados por Piquet Carneiro e mediante um auxílio de pesquisa do governo do Estado da Guanabara, Hesio Cordeiro e Moysés Szklo lideraram um inquérito epidemiológico em uma comunidade da Zona Norte (provavelmente a comunidade do Morro dos Macacos). ${ }^{1}$

A história do IMS foi um desdobramento dessas iniciativas, mas a data exata de sua criação e o documento que a registra não são conhecidos. A menção documental mais antiga ao IMS data de 1970, quando ele aparece mencionado no então instituído Regimento Geral da universidade como uma unidade universitária de ensino e pesquisa vinculada ao Centro Biomédico, também criado na ocasião. Provavelmente, esse regimento é o documento fundacional do instituto.

Piquet Carneiro delegou a tarefa de dar corpo à sua ideia a Hesio Cordeiro, Nina Pereira Nunes (1936-2015) e Moysés Szklo, médicos formados na FCM. Ainda no início dos anos de 1970, Moysés decidiu radicar-se nos Estados Unidos, mais precisamente na Escola de Saúde Pública da Universidade Johns Hopkins, onde em 1980 tornou-se professor titular e trabalhou desde então. Atualmente, está aposentado e colabora com o Instituto de Estudos em Saúde Coletiva da UFRJ.

Nesses primeiros tempos, é essencial mencionar a chegada, também pelas mãos de Piquet Carneiro, de Nelson Luís de Araújo Moraes, sanitarista de formação no conceito norte-americano da Public Health e de grande conceituaçáo no campo da Saúde Pública brasileira. Nelson fez carreira no Serviço Especial de Saúde Pública (SESP) na década de 1960 e no final dessa década assessorou o ministro da Saúde. Entre 1972 e 1973, foi Secretário Geral do ministério (correspondendo atualmente ao cargo de Secretário Executivo), sendo ministro o médico Mário Machado de Lemos, e foi diretor do IMS entre 1971 e 1978. As datas revelam as circunstâncias de sua relação com o IMS - dirigente do ministério durante o governo Médici. Nelson foi um sanitarista SESPIANO típico. Técnico, apolítico, profissional e solidário com seus pares do IMS, não por identidades políticas, mas pelo sentimento de lealdade ao projeto. Durante o período em que foi o número dois do Ministério da Saúde, permaneceu como diretor do IMS e jamais tentou trazer ao instituto as ideias do regime autoritário. Pelo contrário, sua mera presença era uma espécie de ferramenta profilática para barrar eventuais perseguiçôes e repressôes que varriam as universidades e, em particular, a UERJ. 
Ainda com vistas a contextualizar o ambiente acadêmico na UERJ nos primeiros tempos do IMS, vale mencionar que, criada em 1950, apenas em meados da década de 1960 ela, entâo Universidade do Estado da Guanabara, passou a se organizar propriamente como uma universidade. Isso se deu a partir de diretrizes estabelecidas por um grupo de trabalho constituído pelo governo do estado da Guanabara e coordenado pelo vice-governador Raphael de Almeida Magalhães. Paulatinamente, a universidade foi absorvendo o ambiente autoritário e, mais tarde, francamente repressivo da ditadura que naquele momento se constituía. Entre 1967 e 1981, a UERJ teve quatro reitores - Oscar Tenório, Caio Tácito, Ney Palmeiro e João Lyra Filho - todos juristas e o último também poeta. Entretanto, pairando sobre eles durante quase todo esse período, atuou o professor Wilson Choeri. Ele foi, em sequência, diretor do Colégio de Aplicação, diretor do Departamento Cultural, secretário-geral da UERJ (uma espécie de CEO da universidade) na reitoria de João Lyra Filho e, finalmente, vice-reitor. Havia militado no Partido Comunista Brasileiro antes de 1964 e isso lhe criou problemas após o golpe militar, podendo-se especular que tenha contribuído para impedir que chegasse à almejada posição de reitor. Entretanto, sua conversão ao lado direito do espectro político depois de 1964 foi rápida e radical e foi ela que governou a UERJ enquanto ele lá exerceu seu poder. Auxiliado pela centralização administrativa e pelos crescentes relacionamentos com oficiais das Forças Armadas - primeiro, coronéis e depois generais de grande prestígio, tais como Bina Machado e Lyra Tavares (este, irmão do reitor João Lyra Filho) - Choeri conduziu a UERJ com mão de ferro.

Esse esboço, entre outros aspectos, revela a necessidade que o IMS teve de se proteger do ambiente geral que se consolidava na universidade, que, como se verá adiante, teve que ser contornado para que ele pudesse se formalizar institucionalmente. Nessa operação, Hesio, Nina, Piquet Carneiro e Nelson Moraes tiveram papel relevante.

Conheci Hesio Cordeiro em março de 1971, quando cheguei ao Instituto de Medicina Social para cumprir meu último ano do curso médico - o internato. Eu era aluno da Faculdade de Medicina da UFRJ e então era facultada a possibilidade de fazer o internato em outra escola médica reconhecida. Hesio tinha acabado de voltar de Kentucky e outros centros universitários norte-americanos, onde tinha ido fazer estágios de aperfeiçoamento em Ciências do Comportamento e da Conduta Humanas. 
Recordo ainda que Hesio, nos anos seguintes, livrou-se de boa parte da carga da Sociologia funcionalista norte-americana que, entre outros aspectos, passava muito ao largo das suas necessidades intelectuais e das preocupaçóes que nos castigavam naqueles anos de chumbo que se seguiram à edição do Ato Institucional $\mathrm{n}^{\circ}$ 5, de dezembro de 1968. Nesses primeiros anos, pude observar e, lateralmente, participar de dois movimentos político-institucionais que presidiram o processo de consolidação do IMS liderados essencialmente por Hesio e Nina.

O primeiro foi o de afirmar o projeto do IMS no interior da universidade frente à muito reativa corporação médica localizada na FCM, bem como da administração central da universidade que, em boa parte, não tinham apreço pelo projeto do IMS. O segundo foi orientado para fora da universidade, desenvolvido em três frentes e envolveram a Fundação Kellogg, a Organização Panamericana da Saúde (OPAS) e a Financiadora de Estudos e Projetos (FINEP). Seu objetivo central, embora não exclusivo, foi a obtenção de recursos financeiros. $\mathrm{O}$ resultado foi a criação do mestrado em Medicina Social, em 1974.

O primeiro movimento político-institucional - Piquet Carneiro teve papel central no anteparo do IMS frente ao conservadorismo intelectual da maior parte do estamento médico da FCM, em boa parte liderado pelo outro titular de Clínica Médica, judeu conservador com traços anarquistas, Jayme Landmann. As dificuldades na aceitação do IMS pela corporaçâo médica podem ser verificadas em documentos, tais como uma deliberação do Conselho Superior de Ensino e Pesquisa (037/78) que rebaixava o IMS ao nível de um departamento da FCM, a despeito da definição daquele como unidade de ensino e pesquisa no Regimento Geral. Já o seu curso de mestrado, em funcionamento desde 1974, teve seu regimento aprovado apenas em 1982 (Deliberação 080/82). E apenas em 1986 o IMS retomou formalmente suas prerrogativas de unidade acadêmica, com a criação de uma estrutura própria (Deliberação n. 140/86). ${ }^{2}$

Essa "batalha" pelo reconhecimento foi travada também no debate sobre a introdução de disciplinas ministradas pelo IMS no curso médico que, quando implantadas, tomaram os nomes de Ciências do Comportamento Humano e Fundamentos da Saúde na Comunidade. A primeira, que denota já em seu título alguma adesão ao funcionalismo que Hesio trouxe dos Estados Unidos, versava sobre os aspectos "psicossociais" das transiçôes saúde-doença-saúde que, mais tarde, sob novas orientaçôes conceituais, viriam a alimentar tópicos da denominada 
Determinação Social da Saúde e da Doença. Nos Fundamentos da Saúde na Comunidade, tinham lugar as liçóes da epidemiologia/estatística e umas tintas de planejamento em saúde. Essas duas disciplinas eram cursadas na etapa básica da formação médica. O IMS logrou também entrar na etapa clínica do curso médico mediante uma intervenção numa prática tradicional nessa etapa, que são as sessôes clínicas, nas quais casos clínicos reais são discutidos por graduandos, internos, residentes e membros do staff das disciplinas. Essas sessôes passaram a se chamar sessóes clínico-epidemiológicas. Vale, finalmente, mencionar a quase completa falta de prestígio que esse conjunto de intervençóes teve na orientação geral do ensino médico na FCM, seja na época em que foram introduzidas, seja atualmente, naquilo que eventualmente sobreviveu no currículo: inclusive e mais fortemente vocalizadas pelos estudantes. Sob o anteparo de Piquet Carneiro, sem qualquer dúvida devemos essencialmente a Hesio esse movimento inicial de tentar introduzir conceitos da medicina social na formação médica de graduação.

No meu ponto de vista, aliás, foi a consciência das dificuldades no desenvolvimento dessas iniciativas o que está na raiz do segundo dos três processos a que me referi mais acima: as movimentaçóes para fora da universidade que terminaram em apoios financeiros para a organização de um curso de pós-graduação em 1974.

O segundo movimento político-institucional liderado por Hesio, e aqui também por Nina Pereira Nunes, foi a busca de recursos financeiros (e também políticos, como se verá) para a construção desse curso. Ele se deu em três direçóes, sendo a primeira um convênio destinado ao fortalecimento de recursos humanos em saúde com a Fundação Kellogg, instituição filantrópica norte-americana que teve como importante contraparte para sua execução a figura de Mário Chaves (19232015). Esse sanitarista brasileiro teve longa carreira na Fundação SESP, na OPAS, na Organização Mundial da Saúde (OMS), na Escola Nacional de Saúde Pública (ENSP/Fiocruz) e na Federação Pan-Americana de Associações de Faculdades de Medicina. Na primeira metade dos anos 1970, Chaves ocupava o cargo de gestor do programa da Fundação Kellogg na América Latina, que financiou, sob sua direção, vários projetos e programas no Brasil relacionados ao ensino, como os Núcleos de Tecnologia para o ensino profissional na área da Saúde (centros conhecidos como NUTES/CLATES). O convênio com o IMS contribuiu para o financiamento do curso em formação. 
A segunda direção desse movimento político-institucional para a criação da pósgraduação foi articulada junto à OPAS, em particular junto ao seu Departamento de Recursos Humanos, que nessa época contava com a participação de Juan César Garcia (1932-1984), médico argentino (por formação) e cientista social (por atuação política e intelectual). Garcia foi a principal liderança intelectual e política nos anos 1970 na construção de uma vertente crítica latino-americana à saúde pública tradicional e à sociologia funcionalista norte-americana em saúde (com a importante colaboração do médico equatoriano Miguel Marquez [1935-2014]). O principal marco desse movimento em seus passos iniciais foi a realização de um seminário na cidade de Cuenca, no Equador, em 1972, ao qual Hesio compareceu representando o grupo do IMS. Nele, foram lançadas as bases de uma reformulação radical da compreensão da determinação social da saúde e da doença, bem como foi aí costurada uma rede informal de sanitaristas e cientistas sociais reformistas latino-americanos que, alguns anos mais tarde (1983) formalizou-se na Associação Latino-americana de Medicina Social (ALAMES), até hoje ativa. Como parte desse processo, vale mencionar também o seminário realizado em 1978 em Ariccia, perto de Roma, no qual essa articulação latino-americana pôde se expandir para a Europa, com participantes do Reino Unido (Lesley Doyal), França (Antoinette Chauvenet), Espanha (Vicente Navarro) e Itália (Giovanni Berlinguer). Justifica-se a apresentação talvez digressiva desse processo ao longo de toda a década de 1970 porque foi ela que alimentou a maior parte do arcabouço teórico e prático do curso de pós-graduação em Medicina Social do IMS. E foi a partir dele que, sob a liderança de Hesio e de Nina, o curso se estruturou e desenvolveu.

Também durante a década de 1970, dois acontecimentos infames tiveram impacto no IMS que se estruturava, trazendo um importante reforço. $\mathrm{O}$ golpe militar no Chile em 1973 fez chegar no ano seguinte ao IMS José Luís Fiori, que decidiu viver no Rio de Janeiro, e a partir de 1976, um golpe similar na Argentina forneceu ao curso e ao IMS um importante grupo de intelectuais, tendo à frente Mário Testa e Adolfo Chorny. A contribuição deles e de outros que também passaram pelo Rio de Janeiro foi extremamente importante. Mais tarde, Chorny transferiu-se para a ENSP e Testa voltou à Argentina.

A terceira direçáo para a consolidação político-institucional do IMS teve o concurso de uma política educacional, talvez a mais bem-sucedida de todas no Brasil, nascida em 1965 mas que adquiriu velocidade na década seguinte - a política de pós- 
graduação instituída a partir da Capes/MEC. E que a ela, de modo independente, contou com uma revoluçáo nos mecanismos de financiamento à pesquisa no país mediante a designação da Financiadora de Estudos e Projetos (FINEP), em 1971, como secretaria-executiva do Fundo Nacional de Desenvolvimento Científico e Tecnológico (FNDCT), criado em 1969. A FINEP instituiu uma nova modalidade de apoio financeiro à pesquisa que, diferentemente do CNPq, alocava quantidades bem maiores de recursos em instituiçóes e não em pesquisadores individuais. Esses apoios, denominados genericamente de Apoios Institucionais, foram responsáveis por construir parte significativa da capacidade instalada de pesquisa no país, não apenas em saúde. Seus planos de aplicação dos recursos financeiros eram amplos, permitindo, inclusive, a cobertura de despesas com pessoal científico e técnicoadministrativo. Em 1974, Hesio coordenou a elaboração de um projeto que foi apresentado e aprovado pela Finep e que resultou num aporte significativo de recursos para o curso de pós-graduação.

Penso que, muito resumidamente, foram essas iniciativas e articulações que consolidaram, durante toda a década de 1970, o IMS com o seu curso de pósgraduação em Medicina Social como um dos principais centros de produção de conhecimento e de ativismo político-sanitário do país. Isso pode ser indicado pela quantidade de intelectuais que colaboraram de diversas formas com o IMS durante essa década e além. Médicos, epidemiologistas, cientistas políticos, antropólogos, sociólogos, filósofos, psicanalistas, demógrafos, economistas, dentre outros profissionais, cuja presença entre nós dependeu essencialmente da atuação de Hesio, com a permanente colaboração de Nina Pereira Nunes.

Fica bastante claro que a consolidação do IMS frente à UERJ foi um processo cujo principal vetor atuou de fora para dentro. Por um lado, pelo prestígio intelectual de intelectuais nacionais e estrangeiros incorporados e de pesquisadores visitantes ao IMS que colaboraram em diversos graus de intensidade com seu projeto. Por outro, com o aporte de recursos financeiros externos para o ensino e a pesquisa. Ambos impuseram a presença do IMS no ambiente da UERJ. Mais tarde, esse vetor mudou de sentido, pois o prestígio adquirido pelo IMS e por suas projeçóes técnicas e políticas para fora da universidade fizeram com que ele contribuísse para aumentar o prestígio social e acadêmico da própria UERJ como um todo. 
Embora o termo "Saúde Coletiva” já fosse informalmente utilizado desde o início dos anos 1970, teve sua maioridade estabelecida apenas em 1978, no I Encontro Nacional de Pós-Graduação em Saúde Coletiva em Salvador (BA). Daí que não estava ainda nascido no momento da criação do IMS. Essa nova denominação foi estabelecida pelos intelectuais e militantes da saúde na perspectiva de uma tripla não-conformidade com o então estabelecido. Por um lado, porque o termo "Saúde Pública” como expressão das práticas tradicionais da Public Health norte-americana estava longe de se adequar ao pensamento reformista do campo sanitário. Por outro, porque o termo "Medicina Preventiva", muito ligado à saúde pública nos moldes tradicionais e subordinado a esta, era ainda mais restritivo e também eivado do mesmo quadro conceitual do anterior. Finalmente, porque o termo "Medicina Social", fortemente lastreado na concepção europeia reformista do século XIX, que considerava a medicina como uma ciência social, sugeria a exclusão todas as demais práticas profissionais de cuidados à saúde que não fossem médicas.

A escolha do nome do instituto obedeceu a uma conciliação entre as convicçóes reformistas e a circunstância de ele ter nascido das entranhas de uma escola médica. Daí a presença do termo "Medicina Social" no nome do instituto. Dentre as três designaçôes disponíveis naquele momento - medicina preventiva, saúde pública e medicina social - esta última era a que mais se aproximava do reformismo dos jovens fundadores, ao mesmo tempo que preservava a condição médica homenageando seu local de nascimento, ao gosto do "velho" professor que o havia inspirado. Na década seguinte, houve um crescente debate sobre a oportunidade do termo "medicina", se não no nome do IMS, pelo menos nos títulos de mestrado e doutorado que o curso de pós-graduação (agora denominado um "programa”) outorgava, haja vista o concurso cada vez maior de profissionais não-médicos como alunos. Debate resolvido em 1987, quando o curso de pós-graduação, até então de "Medicina Social”, passou a chamar-se "Saúde Coletiva".

$\mathrm{Na}$ minha visão, uma síntese das qualidades que Hesio desenvolveu durante sua vida podem ser expressas em habilidade política e capacidade de agregação de pessoas a um projeto. Foram essas duas características as que permitiram que, partindo de um pequeno grupo de médicos liderados por ele e por Nina Pereira Nunes, o IMS pudesse reunir tantos profissionais das mais variadas formaçóes e interesses numa unidade acadêmica nova e de pouco prestígio nas fontes de poder da universidade em que estava situado. Hesio, um mineiro de Juiz de Fora, teve a enorme habilidade de 
conciliar, internamente, os interesses e eventuais idiossincrasias desses profissionais, bem como, externamente, fazer com que o conservadorismo universitário não o matasse e, mais tarde, passasse a admirá-lo no plano acadêmico.

Até agora este resgate histórico tematizou o papel de Hesio como fundador, organizador e consolidador do IMS. Mas Hesio, além disso, foi também um intelectual importante no campo da Saúde Coletiva. Sua obra no campo do ensino e da pesquisa abraçou essencialmente três áreas. As políticas de saúde, o complexo industrial da saúde e a educação em saúde, em particular a educação médica. Como veremos a seguir, foi na área da pesquisa em políticas de saúde que sua presença foi mais marcante.

Entre 1968 e 1984, fez publicar 36 artigos em revistas, dois livros e cinco capítulos de livros. Até 1977, seus temas envolveram predominantemente aspectos de epidemiologia clínica vinculados a patologias específicas. Em seguida, até 1984, aparecem artigos sobre política de saúde e sobre o complexo industrial da saúde, este um objeto de estudo então inexplorado no campo da Saúde Coletiva. A Hesio devemos o primeiro conceito que articulava a indústria às práticas da saúde que ele denominou "complexo médico-industrial". Além disso, também se voltou para o estudo da educação em saúde, em especial a educação médica. Sua dissertação de mestrado e tese de doutorado foram publicadas respectivamente em 1981 e 1984, e intituladas A Indústria da Saúde no Brasil e As Empresas Médicas: as transformaçôes capitalistas da prática médica. Colaborou ainda com cinco capítulos de livros, predominantemente sobre a indústria farmacêutica no Brasil. Ao longo de sua carreira, orientou 25 dissertaçóes de mestrado e quatro teses de doutoramento.

Esses três grandes temas cobertos por Hesio durante sua trajetória de pesquisador e professor no IMS, bem como sua participação no movimento latino-americano que construiu um arcabouço crítico dos sistemas de saúde em seus países, puderam configurar uma visão abrangente e orientada do que poderia ser uma reforma do sistema público de saúde - uma Reforma Sanitária - no Brasil. Na construção desse projeto, até hoje inconcluso, Hesio teve papel central, com uma particularidade rara: ele foi capaz de imaginar as linhas gerais da reforma, grosso modo entre 1975 e 1980, em seguida trabalhou no detalhamento do projeto até 1985, e pôde testar as teses imaginadas até então, realizando, como presidente do Instituto de Assistência Médica 
da Previdência Social (INAMPS), a reforma do modelo assistencial, deslocando-o do sistema de previdência social para o futuro Sistema Único de Saúde, criado em 1990. Em artigo publicado nesta Physis em 2004, Hesio recorda boa parte dessa trajetória (CORDEIRO, 2004).

Uma abordagem política e sintética da construção intelectual desenvolvida no Instituto de Medicina Social está posta em um documento de 1976, intitulado "A questáo democrática na área da Saúde". ${ }^{3}$ Embora assinado por três professores, ele reflete em boa parte a trajetória intelectual e política de Hesio Cordeiro como principal liderança do IMS.

Recentemente, em outubro de 2020, José Luís Fiori escreveu um texto sobre esse documento, no qual, ao lado de homenagear Hesio, analisa o papel do IMS no período de construção da Reforma Sanitária. Penso não haver necessidade de complementar qualquer aspecto dessa empreitada intelectual e política e do papel central jogado por ele. Desse modo, remeto o leitor ao texto de Fiori, também publicado neste dossiê.

\section{Referência}

CORDEIRO, H. A. O Instituto de Medicina Social e a Luta pela Reforma Sanitária: contribuição à história do SUS. Physis: Rev. Saúde Coletiva, Rio de Janeiro, v. 14, n. 2, p. 343-362, 2004.

\section{Notas}

${ }^{1}$ Agradeço a Moyses Szklo a informação sobre o ambulatório e o inquérito. A especulação sobre o local da pesquisa é exclusivamente minha.

${ }^{2}$ Agradeço a Maria Del Carmen Corrales, servidora técnico-administrativa da UERJ, a obtenção desses documentos.

${ }^{3}$ Publicado neste dossiê. 